\title{
The black box model of a double-tube counter-flow heat exchanger
}

\author{
Rafał Laskowski
}

Received: 18 January 2014 / Accepted: 18 December 2014 / Published online: 25 December 2014

(C) The Author(s) 2014. This article is published with open access at Springerlink.com

\begin{abstract}
Variable working conditions of a double-tube counter-flow heat exchanger were analysed. During operation of the heat exchanger, the parameters (temperatures and mass flow rates) of both fluids at its inlet change, which leads to a change in its performance. Heat transfer effectiveness is commonly used to assess the heat exchanger performance, defined as the ratio of the actual to the maximum heat flow rate. In the present paper, the heat exchanger was considered to be a 'black box', and the aim was to investigate how the inlet parameters (temperatures and mass flow rates of both fluids) affect the outlet ones (temperatures of both fluids), and thus to attempt to introduce a new relation for the heat transfer effectiveness of a counter-flow heat exchanger as a function of only inlet parameters. Following the analysis, a relation for the heat transfer effectiveness as a function of inlet parameters with five constant coefficients was obtained. These coefficients depend on the heat exchanger geometry and on the properties of the heat transfer fluids; they are not general-purpose, but specific to a counter-flow heat exchanger. The form of the proposed relation for the heat transfer effectiveness of a counter-flow heat exchanger is not satisfactory as it involves five constant coefficients; therefore, a new approach was chosen, consisting in analysing a parameter defined as the ratio of the minimum to the actual arithmetic mean temperature difference. Using the parameter defined in this way, the relation for the heat transfer effectiveness of a counter-flow heat exchanger was obtained as a function of two parameters: the ratio of
\end{abstract}

R. Laskowski $(\bowtie)$

Institute of Heat Engineering, Warsaw University of Technology, 21/25 Nowowiejska Street, 00-665 Warsaw, Poland

e-mail: rlask@itc.pw.edu.pl the heat capacity rates of both fluids, and $N T U$, with no constant coefficients. The proposed relations were verified against the data produced by a simulator of a double-tube counter-flow heat exchanger.

\section{List of symbols}

A Heat transfer surface area $\left(\mathrm{m}^{2}\right)$

$A_{1} ; A_{2} ; A_{3} ; A_{4} ; A_{5}$ Constant coefficients

$a_{1} ; a_{2} ; a_{3} ; a_{4} ; a_{5} ; a_{6} ; a_{7} ; a_{8} ; a_{9} ; a_{10}$ Constant coefficients

$\dot{C} \quad$ Fluid heat capacity $(\mathrm{W} / \mathrm{K})$

$C \quad$ Heat capacity rate ratio (-)

$\dot{m} \quad$ Mass flow rate $(\mathrm{kg} / \mathrm{s})$

$N T U \quad$ Number of heat transfer units $\left(N T U=\frac{U A}{\dot{C}_{2}}\right)$

$T \quad$ Temperature $\left({ }^{\circ} \mathrm{C}\right)$

$U \quad$ Overall heat transfer coefficient $\left[\mathrm{W} /\left(\mathrm{m}^{2} \mathrm{~K}\right)\right]$

$\dot{Q} \quad$ Heat flow (W)

$\dot{Q}_{\max } \quad$ Maximum heat flow (W)

$\alpha \quad$ The ratio of the minimum to the actual arithmetic mean temperature difference (-)

$\varepsilon \quad$ Heat transfer effectiveness (-)

$\Delta T_{a} \quad$ Arithmetic mean temperature difference $\left({ }^{\circ} \mathrm{C}\right)$

$\Delta T_{a \min }$ Minimum arithmetic mean temperature difference $\left({ }^{\circ} \mathrm{C}\right)$

$\Delta T_{1} \quad$ The difference between the hot fluid outlet temperature and the cold fluid inlet temperature $\left(\Delta T_{1}=T_{h 2}-T_{c 1}\right)\left[{ }^{\circ} \mathrm{C}\right]$

$\Delta T_{2} \quad$ The difference between the hot fluid inlet temperature and the cold fluid outlet temperature $\left(\Delta T_{2}=T_{h 1}-T_{c 2}\right)\left[{ }^{\circ} \mathrm{C}\right]$

\section{Index}

c Cold fluid

$h \quad$ Hot fluid

$1 \quad$ Inlet

2 Outlet 


\section{Introduction}

Counter-flow heat exchangers are widely used in food and refinery industry and are an important element of various types of installations.

In a counter-flow heat exchanger, the heat transfer fluids flow in opposite directions. Figure 1 is a diagram of a double-tube counter-flow heat exchanger, illustrating the notation used and the flow directions of both fluids. In this case, the hot fluid flows inside the inner tube, while the heated one inside the outer tube [1-6].

The temperature profile along the length of the counterflow heat exchanger under consideration for both fluids is shown in Fig. 2 [1-6].

During operation of the counter-flow heat exchanger, variations in temperatures $\left(T_{h 1} ; T_{c 1}\right)$ and mass flow rates $\left(\dot{m}_{h}, \dot{m}_{c}\right)$ at the inlet of the heat exchanger may occur, which affects the heat exchanger performance. Counterflow heat exchangers are often part of a more complex system, and changes in their performance affect the behaviour of the entire system. Therefore, it is important to know the performance of a counter-flow heat exchanger in offdesign conditions. To assess its performance, the first and second law of thermodynamics [5, 7-9] are utilized. From the first law of thermodynamics and Peclet's law a concept of effectiveness can be derived. Heat transfer effectiveness

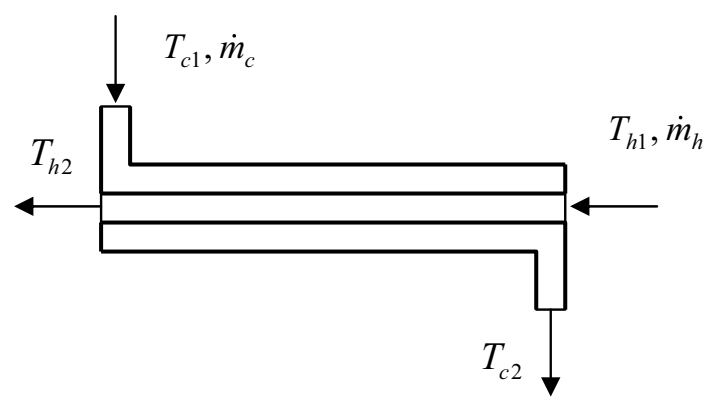

Fig. 1 Counter-flow heat exchanger diagram with the notation used

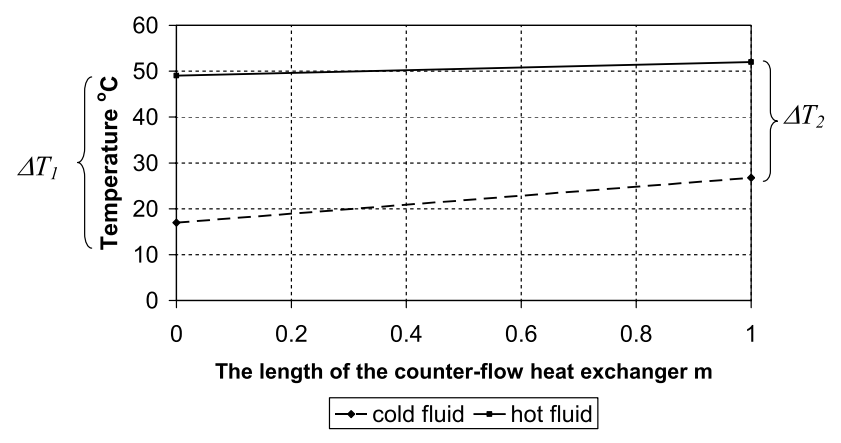

Fig. 2 Temperature distribution along the length of the counter-flow heat exchanger under consideration is commonly used to describe the heat exchanger performance under off-design conditions, defined as the ratio of the actual to the maximum heat flow rate [1-5].

$\varepsilon=\frac{\dot{Q}}{\dot{Q}_{\max }}$

Other quantities are also used to assess the exchanger performance, e.g. the heat exchanger efficiency defined as the ratio of the actual to the optimum rate of heat transfer [1012]. To determine the performance of heat exchangers, the required, or obtained, heat transfer units [13] were also proposed. For a counter-flow heat exchanger, the heat transfer effectiveness is a function of two parameters: $N T U$ and $C$; it has the following form [1-5]:

$\varepsilon=\frac{1-\exp [(C-1) \cdot N T U]}{1-C \cdot \exp [(C-1) \cdot N T U]}$

Parameter $C$ is a ratio of heat capacity rates of both fluids: $C=\frac{\dot{C}_{2}}{\dot{C}_{1}}$; the numerator is the smaller heat capacity rate of one fluid, while the denominator is the larger heat capacity rate of the other fluid. The fluid heat capacity rate is a product of specific heat at constant pressure and the mass flow rate: $\dot{C}=c_{p} \dot{m}$. The parameter $N T U$ is equal to a product of an overall heat transfer coefficient and the heat transfer surface area, divided by the smaller fluid heat capacity $N T U=\frac{U A}{C_{2}}$.

The analytical solution for the effectiveness of a counterflow heat exchanger in which a uniform, external heat load is applied to one or both sides is presented in [14].

In order to determine the effectiveness of a counter-flow heat exchanger according to relation (2), more equations are needed, e.g. for heat transfer coefficients of both fluids, the overall heat transfer coefficient and the thermodynamic functions, to calculate thermodynamic properties of the fluids, such as specific heat, viscosity, thermal conductivity, and density. All these relations form a set of equations. The thermodynamic properties should be calculated for average fluid temperatures; therefore, the calculations must be carried out iteratively, because the outlet temperatures are not known. Based on the set of equations, simulators of counter-flow heat exchangers have been created $[6,15,16]$.

In the literature, approximate relations can also be found that allow to determine the effectiveness of the counterflow heat exchanger quickly and with good accuracy as a function of the number of transfer units and the ratio of the heat capacity rates $[17,18]$.

In the article, yet another approach was taken to describe the effectiveness of the counter-flow heat exchanger. It was decided to treat the counter-flow heat exchanger as a "black box' to examine how input variables affect the output variables, and, on this basis, to propose an approximate relation describing the performance of the counter-flow heat exchanger in off-design conditions. 
The overall heat transfer coefficient $U$ is mainly the function of velocities [mass flow rates $\left(\dot{m}_{h}, \dot{m}_{c}\right)$ ] of both fluids and the temperatures $\left(T_{h 1} ; T_{c 1}\right)$ at the inlet of the heat exchanger. Assuming that the thermodynamic properties of the fluids are constant ( $c_{p}=$ const), one can define the heat transfer effectiveness as a function of the following parameters at the inlet of the heat exchanger:

$\varepsilon=f\left(T_{h 1}, T_{c 1}, \dot{m}_{h}, \dot{m}_{h}\right.$, type of heat exchanger $)$

In this paper, an attempt was made to produce a relation for the heat transfer effectiveness as a function of the parameters only at the inlet of the heat exchanger (temperatures and mass flow rates). To this end, the counter-flow heat exchanger was considered as a 'black box' (Fig. 3), and the effect of each of the inlet variables on the outlet variables was investigated. The inlet variables were: temperatures $\left(T_{h 1} ; T_{c 1}\right)$ and mass flow rates $\left(\dot{m}_{h}, \dot{m}_{c}\right)$ at the inlet of the heat exchanger. The outlet variables were: the temperatures of the fluids at the outlet of the heat exchanger $\left(T_{h 2} ; T_{c 2}\right)$.

\section{The mathematical model}

\subsection{The black box model of the heat exchanger}

This model was used to investigate how the inlet parameters (temperatures and mass flow rates of both fluids at the inlet of the heat exchanger) affect the outlet parameters (temperatures of both fluids at the outlet of the heat exchanger).

The outlet temperature of the cold fluid can be written as (Fig. 2)

$T_{c 2}=T_{h 1}-\Delta T_{2}$

The relation (4) can be converted to a form involving the heat transfer effectiveness:

$\varepsilon=\frac{T_{c 2}-T_{c 1}}{T_{h 1}-T_{c 1}}=1-\frac{\Delta T_{2}}{T_{h 1}-T_{c 1}}$

The temperature difference $\left(\Delta T_{2}=T_{h 1}-T_{c 2}\right)$ and the heat transfer effectiveness depend on the same independent variables:

$\Delta T_{2}=f\left(T_{h 1}, T_{c 1}, \dot{m}_{h}, \dot{m}_{h}\right.$, type of heat exchanger $)$

The effect of each of the independent variables on the temperature difference $\left(\Delta T_{2}\right)$ was analysed. One independent variable was assumed to vary; other independent variables were constant:

$\Delta T_{2}=f\left(T_{h 1}\right)$

$\Delta T_{2}=f\left(T_{c 1}\right)$

$\Delta T_{2}=f\left(\dot{m}_{c}\right)$

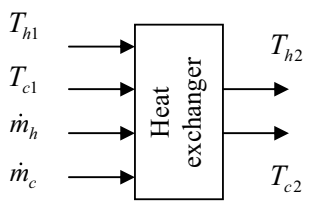

Fig. 3 Parameters at the inlet and outlet of the counter-flow heat exchanger

$\Delta T_{2}=f\left(\dot{m}_{h}\right)$

Based on the data produced by a counter-flow heat exchanger simulator, linear relations between the temperature difference $\left(\Delta T_{2}\right)$ and the temperatures at the inlet of the heat exchanger were obtained.

$\Delta T_{2}=a_{1} T_{c 1}+a_{2}$

$\Delta T_{2}=a_{3} T_{h 1}+a_{4}$

Taking into account $(11,12)$, the effect of the change in the inlet temperature $\left(T_{h 1} ; T_{c 1}\right)$ on the temperature difference $\left(\Delta T_{2}\right)$ can take the form

$\Delta T_{2}=a_{1} T_{c 1}+a_{3} T_{h 1}+a_{2}+a_{4}$

The relation for the temperature difference $\left(\Delta T_{2}\right)$ as a function of the inlet temperatures $\left(T_{h 1} ; T_{c 1}\right)$ is linear (13). However, it was difficult to find appropriate functions to describe the relation for the temperature difference $\left(\Delta T_{2}\right)$ as a function of mass flow rates $\left(\dot{m}_{h}, \dot{m}_{c}\right)$. Attempts were made to approximate these relations using various functions but with no satisfactory results. Therefore, the relation for the temperature difference $\left(\Delta T_{2}\right)$ as a function of mass flow rates $\left(\dot{m}_{h}, \dot{m}_{c}\right)$ was shown using logarithmic coordinates. This approach also allowed to obtain, approximately, a linear relation for the temperature difference $\left(\Delta T_{2}\right)$ as a function of mass flow rates. Since the arguments of a logarithmic function were required not to be dimensional quantities, the mass flow rates were divided by a reference mass of $1 \mathrm{~kg} / \mathrm{s}$, and similarly the temperature differences $\Delta T_{2}$ were divided by $1{ }^{\circ} \mathrm{C}$.

$\ln \left(\Delta T_{2}\right)=a_{5} \ln \left(\dot{m}_{h}\right)+a_{6}$

$\ln \left(\Delta T_{2}\right)=a_{7} \ln \left(\dot{m}_{c}\right)+a_{8}$

Taking into account $(14,15)$, the effect of the change in the mass flow rates of both fluids $\left(\dot{m}_{h}, \dot{m}_{c}\right)$ on the temperature difference $\left(\Delta T_{2}\right)$ can be written as

$\ln \left(\Delta T_{2}\right)=a_{5} \ln \left(\dot{m}_{h}\right)+a_{7} \ln \left(\dot{m}_{c}\right)+a_{6}+a_{8}$

The relation (16) can be transformed into

$\Delta T_{2}=C\left(\frac{\dot{m}_{c}}{\dot{m}_{h}}\right)^{a_{9}}\left(\dot{m}_{h}\right)^{a_{10}}$ 
Following the analysis of the relations (13 and 17) one can write:

$\Delta T_{2}=\left(A_{1} T_{c 1}+A_{2} T_{h 1}+A_{3}\right)\left(\frac{\dot{m}_{c}}{\dot{m}_{h}}\right)^{A_{4}}\left(\dot{m}_{h}\right)^{A_{5}}$

The proposed relations (18 and 5) were verified against the data produced by a simulator of a double tube counterflow heat exchanger. In the simulator, common relations for heat transfer coefficients relevant to a turbulent flow $[3,4,19-21]$ for both fluids were used. Water was used as heat transfer fluids. The hot fluid was flowing inside the smaller tube, while the cold one inside the larger tube. For the purpose of simplification, the overall heat transfer coefficient $(U)$ was calculated as in the case of a flat wall $[3,4,22,23]$. The outer diameters were $0.03 \mathrm{~m}$ (the inner tube) and $0.043 \mathrm{~m}$ (the outer tube). The length of the heat exchanger was $1 \mathrm{~m}$. The inlet parameters varied within the following ranges: the temperature of the hot fluid $T_{h 1}<48$; $52>^{\circ} \mathrm{C}$; the temperature of the cold fluid $T_{c 1}<17 ; 21>^{\circ} \mathrm{C}$; the mass flow rate of the hot fluid $\dot{m}_{h}<0.1 ; 0.5>\mathrm{kg} / \mathrm{s}$; the mass flow rate of the cold fluid $\dot{m}_{c}<0.03 ; 0.07>\mathrm{kg} / \mathrm{s}$. The cases where heat capacity rates of both fluids were equal were also considered. For equal heat capacity rates, the values were chosen from one or the other range of changes in the mass flow rate. Another example of a double-tube counter-flow heat exchanger simulator along with the ranges of inlet parameter variations can be found in the literature [6].

\subsection{Heat exchanger model based on the ratio of the minimum and the actual arithmetic mean temperature difference}

The proposed relation (18) is a function of inlet parameters but it contains five constant coefficients which need to be determined based on the real or simulator data. These coefficients vary depending on the counter-flow heat exchangerspecific geometry (inner and outer diameter, length, etc.) and on the fluid (water, air, etc.). Since no general-purpose relation could be produced for the heat transfer effectiveness of a counter-flow heat exchanger as a function of inlet parameters, another approach was chosen, namely to analyse the ratio of the minimum to the actual arithmetic mean temperature difference and to investigate possible solutions (Fig. 2).

$\frac{\Delta T_{a \min }}{\Delta T_{a}}=\frac{\Delta T_{1} / 2}{\left(\Delta T_{1}+\Delta T_{2}\right) / 2}=\frac{\Delta T_{1}}{\Delta T_{1}+\Delta T_{2}}$

It was assumed that, with good approximation, the logarithmic mean temperature difference can be replaced by the arithmetic mean temperature difference (Fig. 2) [3, 4, 21, $24,25]$.The relation (19) can be transformed into

$\frac{\Delta T_{1}}{\Delta T_{1}+\Delta T_{2}}=\frac{\left(T_{c 2}-T_{c 1}\right)\left(1-\frac{T_{h 1}-T_{h 2}}{T_{c 2}-T_{c 1}}\right)}{\frac{4\left[T_{h 2}+T_{h 1}-\left(T_{c 2}+T_{c 1}\right)\right]}{2}}+\frac{1}{2}$

The following stems from the heat exchanger energy balance:

$C=\frac{\dot{C}_{2}}{\dot{C}_{1}}=\frac{T_{h 1}-T_{h 2}}{T_{c 2}-T_{c 1}}$

According to the Peclet's law, assuming that, with good approximation, the logarithmic mean temperature difference can be replaced by the arithmetic mean temperature difference, the following can be written:

$N T U=\frac{U A}{\dot{C}_{2}}=\frac{\left(T_{c 2}-T_{c 1}\right)}{\frac{\left[T_{h 2}+T_{h 1}-\left(T_{c 2}+T_{c 1}\right)\right]}{2}}$

Finally, the relation (20), noted as the parameter $(\alpha)$, can be written as

$\alpha=\frac{\Delta T_{1}}{\Delta T_{1}+\Delta T_{2}}=\frac{N T U}{4}(1-C)+\frac{1}{2}$

Whereas

$\frac{\Delta T_{1}}{\Delta T_{1}+\Delta T_{2}}+\frac{\Delta T_{2}}{\Delta T_{1}+\Delta T_{2}}=1$

From the relations (24 and 23) it follows that

$\frac{\Delta T_{2}}{\Delta T_{1}+\Delta T_{2}}=\frac{1}{2}-\frac{N T U}{4}(1-C)$

By dividing the relation (23) by (25), a relation is obtained between the temperature difference at the front and at the back of the heat exchanger (Fig. 2) and the ratio of heat capacity rates and $N T U$.

$\frac{\Delta T_{1}}{\Delta T_{2}}=\frac{\frac{N T U}{4}(1-C)+\frac{1}{2}}{\frac{1}{2}-\frac{N T U}{4}(1-C)}$

The relation (23) can be transformed into

$\Delta T_{2}=\frac{(C-1)(1-\alpha)}{C-\alpha C-\alpha}\left(T_{h 1}-T_{c 1}\right)$

Taking into account $(5,27)$, the heat transfer effectiveness of a counter-flow heat exchanger can be approximately written as

$\varepsilon=\frac{T_{c 2}-T_{c 1}}{T_{h 1}-T_{c 1}}=1-\frac{(C-1)(1-\alpha)}{C-\alpha C-\alpha}=1-\frac{(1-C)(1-\alpha)}{\alpha+\alpha C-C}$ 


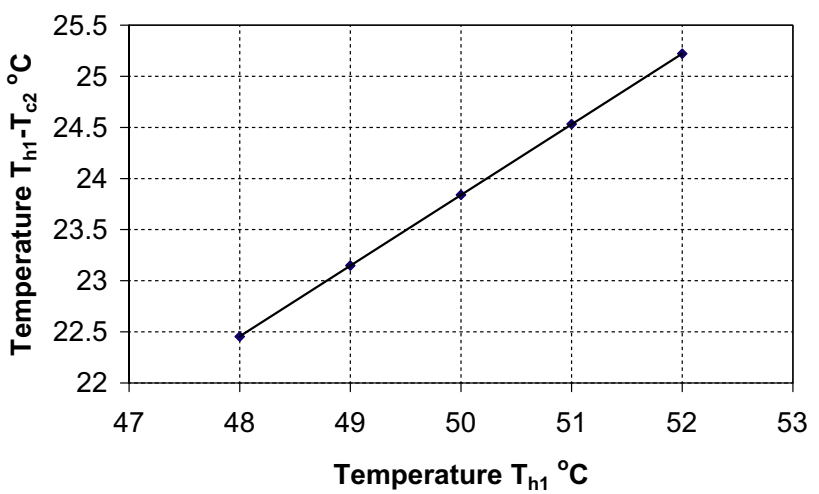

Fig. 4 The effect of the temperature change $\left(T_{h 1}\right)$ on the temperature difference $\left(\Delta T_{2}\right)$

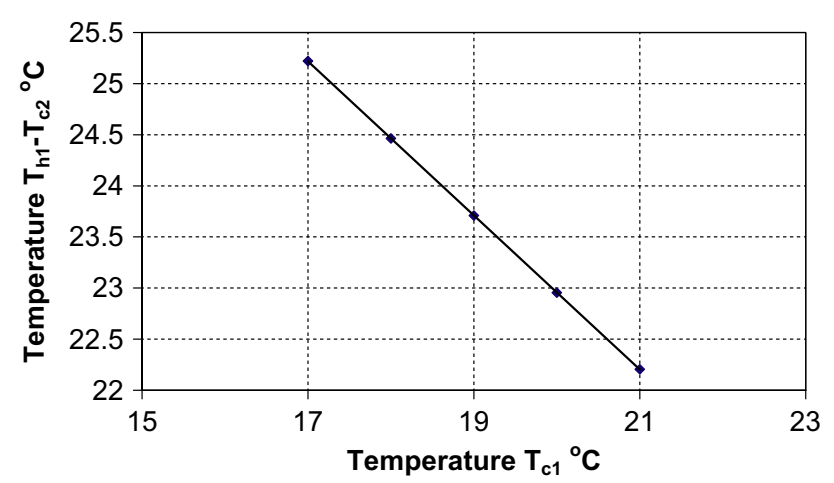

Fig. 5 The effect of the temperature change $\left(T_{c 1}\right)$ on the temperature difference $\left(\Delta T_{2}\right)$

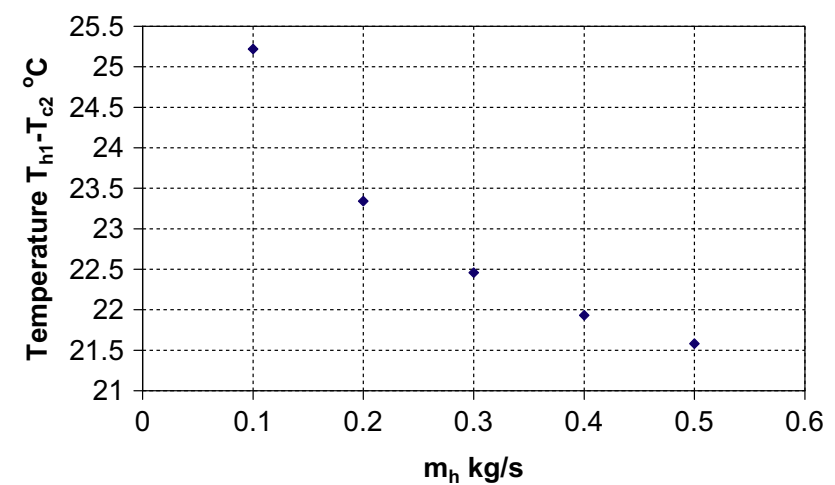

Fig. 6 The effect of the change in the mass flow rate $\left(\dot{m}_{h}\right)$ on the temperature difference $\left(\Delta T_{2}\right)$

The proposed relations for the temperature difference $\Delta T_{2}$ (27) and the heat transfer effectiveness (28) contain no constant coefficients and are functions of two variables $(C$; $N T U$ ). In order to determine $N T U$, the overall heat transfer coefficient $U$ needs to be determined.

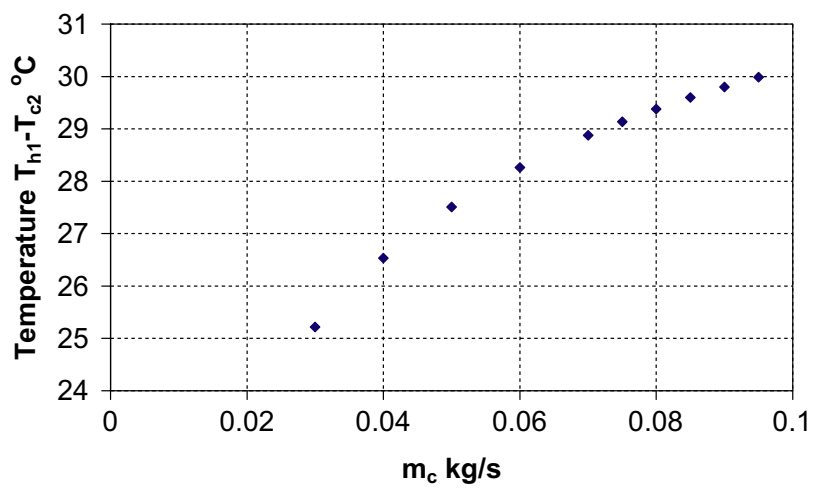

Fig. 7 The effect of the change in the mass flow rate $\left(\dot{m}_{c}\right)$ on the temperature difference $\left(\Delta T_{2}\right)$

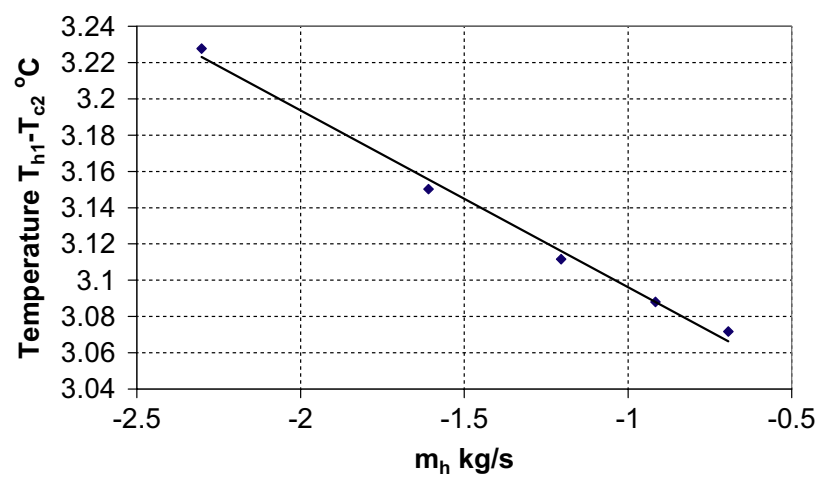

Fig. 8 The effect of the change in the mass flow rate $\left(\dot{m}_{h}\right)$ on the temperature difference $\left(\Delta T_{2}\right)$ in logarithmic coordinates

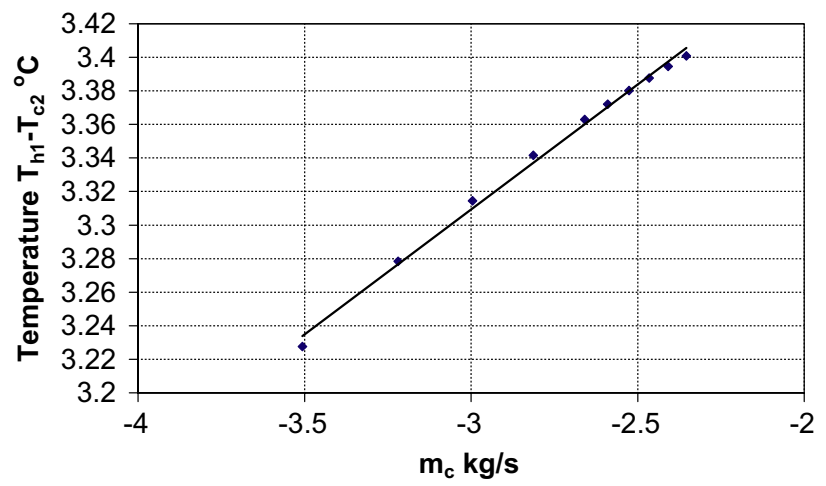

Fig. 9 The effect of the change in the mass flow rate $\left(\dot{m}_{c}\right)$ on the temperature difference $\left(\Delta T_{2}\right)$ in logarithmic coordinates

\section{Results}

3.1 Results of the black box model

Using the data produced by a simulator of a double-tube counter-flow heat exchanger, the effect of inlet variables 


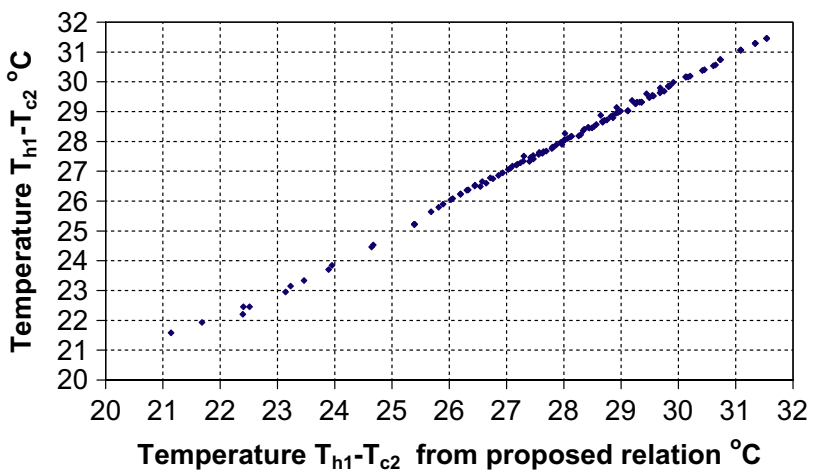

Fig. 10 A comparison between the temperature difference $\left(\Delta T_{2}\right)$ as obtained using the data from the simulator and as calculated from the proposed relation (18)

(the temperatures at the inlet of the heat exchanger and the mass flow rates of both fluids) on the temperature difference $\Delta T_{2}$ was analysed.

The effect of the change in the hot fluid temperature $\left(T_{h 1}\right)$ and the cold fluid temperature $\left(T_{c 1}\right)$ on the temperature difference $\left(\Delta T_{2}\right)$ is shown in Figs. 4 and 5, respectively.

Based on the data shown in Fig. 4, it can be observed that the change in the hot fluid temperature at the inlet of the heat exchanger has a linear effect on the temperature difference $\Delta T_{2}$.
The change in the cold fluid temperature at the inlet of the heat exchanger has also a linear effect on the temperature difference $\Delta T_{2}$ (Fig. 5). The effect of the change in the hot fluid mass flow rate $\left(\dot{m}_{h}\right)$ and the cold fluid mass flow rate $\left(\dot{m}_{c}\right)$ on the temperature difference $\left(\Delta T_{2}\right)$ is shown in Figs. 6 and 7, respectively.

The change in the hot fluid mass flow rate has no linear effect on the temperature difference $\left(\Delta T_{2}\right)$ (Fig. 6).

Similarly, the effect of the change in the cold fluid mass flow rate on the temperature difference $\left(\Delta T_{2}\right)$ is not linear (Fig. 7). Attempts were made to approximate the variation path presented in Figs. 6 and 7 using various functions but with no satisfactory results. Therefore, it was decided to show the nature of the variations in these quantities using logarithmic coordinates.

The effect of the change in the mass flow rate $\left(\dot{m}_{h}\right)$ and the mass flow rate $\left(\dot{m}_{c}\right)$ on the temperature difference $\left(\Delta T_{2}\right)$ in logarithmic coordinates is shown in Figs. 8 and 9, respectively.

Based on the data in logarithmic coordinates as shown in Figs. 8 and 9, the effect of mass flow rates on the temperature difference $\left(\Delta T_{2}\right)$ can be well approximated using simple functions $(14,15)$.

The comparison between the temperature difference $\left(\Delta T_{2}\right)$ obtained using the data from the simulator and the one calculated from the proposed relation (18) is shown in Fig. 10.

Table 1 Data concerning the counter-flow heat exchanger under consideration (different mass flow rates of both fluids)

\begin{tabular}{|c|c|c|c|c|c|c|c|c|}
\hline$T_{c 1}\left[{ }^{\circ} \mathrm{C}\right]$ & $T_{h 1}\left[{ }^{\circ} \mathrm{C}\right]$ & $\dot{m}_{c}[\mathrm{~kg} / \mathrm{s}]$ & $\dot{m}_{h}[\mathrm{~kg} / \mathrm{s}]$ & $T_{c 2}\left[{ }^{\circ} \mathrm{C}\right]$ & $T_{h 2}\left[{ }^{\circ} \mathrm{C}\right]$ & $\Delta T_{2}\left[{ }^{\circ} \mathrm{C}\right]$ from relation $(18)$ & $\Delta T_{2}\left[{ }^{\circ} \mathrm{C}\right]$ & Difference $\left[{ }^{\circ} \mathrm{C}\right]$ \\
\hline 17 & 52 & 0.03 & 0.1 & 26.78 & 49.06 & 25.39 & 25.22 & -0.17 \\
\hline 18 & 52 & 0.03 & 0.1 & 27.54 & 49.14 & 24.64 & 24.46 & -0.18 \\
\hline 19 & 52 & 0.03 & 0.1 & 28.29 & 49.21 & 23.89 & 23.71 & -0.18 \\
\hline 20 & 52 & 0.03 & 0.1 & 29.04 & 49.28 & 23.14 & 22.96 & -0.19 \\
\hline 21 & 52 & 0.03 & 0.1 & 29.79 & 49.36 & 22.39 & 22.21 & -0.19 \\
\hline 17 & 51 & 0.03 & 0.1 & 26.47 & 48.16 & 24.67 & 24.53 & -0.14 \\
\hline 17 & 50 & 0.03 & 0.1 & 26.16 & 47.25 & 23.95 & 23.84 & -0.11 \\
\hline 17 & 49 & 0.03 & 0.1 & 25.85 & 46.34 & 23.23 & 23.15 & -0.08 \\
\hline 17 & 48 & 0.03 & 0.1 & 25.55 & 45.43 & 22.51 & 22.45 & -0.06 \\
\hline 17 & 52 & 0.04 & 0.1 & 25.47 & 48.61 & 26.45 & 26.53 & 0.08 \\
\hline 17 & 52 & 0.05 & 0.1 & 24.49 & 48.25 & 27.30 & 27.51 & 0.20 \\
\hline 17 & 52 & 0.06 & 0.1 & 23.74 & 47.95 & 28.02 & 28.26 & 0.24 \\
\hline 17 & 52 & 0.07 & 0.1 & 23.13 & 47.71 & 28.64 & 28.87 & 0.23 \\
\hline 17 & 52 & 0.075 & 0.1 & 22.86 & 47.60 & 28.92 & 29.14 & 0.21 \\
\hline 17 & 52 & 0.08 & 0.1 & 22.62 & 47.50 & 29.19 & 29.38 & 0.19 \\
\hline 17 & 52 & 0.085 & 0.1 & 22.40 & 47.40 & 29.44 & 29.60 & 0.15 \\
\hline 17 & 52 & 0.09 & 0.1 & 22.20 & 47.31 & 29.68 & 29.80 & 0.12 \\
\hline 17 & 52 & 0.095 & 0.1 & 22.01 & 47.23 & 29.91 & 29.99 & 0.08 \\
\hline 17 & 52 & 0.03 & 0.2 & 28.66 & 50.25 & 23.46 & 23.34 & -0.12 \\
\hline 17 & 52 & 0.03 & 0.3 & 29.54 & 50.74 & 22.41 & 22.46 & 0.05 \\
\hline 17 & 52 & 0.03 & 0.4 & 30.07 & 51.02 & 21.69 & 21.93 & 0.25 \\
\hline 17 & 52 & 0.03 & 0.5 & 30.42 & 51.19 & 21.14 & 21.58 & 0.44 \\
\hline
\end{tabular}


Table 2 Data concerning the counter-flow heat exchanger under consideration (equal mass flow rates of both fluids)

\begin{tabular}{|c|c|c|c|c|c|c|c|c|}
\hline$T_{c 1}\left[{ }^{\circ} \mathrm{C}\right]$ & $T_{h 1}\left[{ }^{\circ} \mathrm{C}\right]$ & $\dot{m}_{c}[\mathrm{~kg} / \mathrm{s}]$ & $\dot{m}_{h}[\mathrm{~kg} / \mathrm{s}]$ & $T_{c 2}\left[{ }^{\circ} \mathrm{C}\right]$ & $T_{h 2}\left[{ }^{\circ} \mathrm{C}\right]$ & $\Delta T_{2}\left[{ }^{\circ} \mathrm{C}\right]$ from relation $(18)$ & $\Delta T_{2}\left[{ }^{\circ} \mathrm{C}\right]$ & Difference $\left[{ }^{\circ} \mathrm{C}\right]$ \\
\hline 17 & 52 & 0.03 & 0.03 & 22.97 & 46.02 & 29.12 & 29.03 & -0.09 \\
\hline 17 & 52 & 0.04 & 0.04 & 22.68 & 46.31 & 29.36 & 29.32 & -0.04 \\
\hline 17 & 52 & 0.05 & 0.05 & 22.47 & 46.52 & 29.54 & 29.53 & -0.01 \\
\hline 17 & 52 & 0.06 & 0.06 & 22.30 & 46.69 & 29.70 & 29.70 & 0.00 \\
\hline 17 & 52 & 0.07 & 0.07 & 22.16 & 46.84 & 29.83 & 29.84 & 0.02 \\
\hline 17 & 52 & 0.1 & 0.1 & 21.84 & 47.15 & 30.13 & 30.16 & 0.03 \\
\hline 17 & 52 & 0.2 & 0.2 & 21.26 & 47.74 & 30.73 & 30.74 & 0.01 \\
\hline 17 & 52 & 0.3 & 0.3 & 20.93 & 48.06 & 31.09 & 31.07 & -0.02 \\
\hline 17 & 52 & 0.4 & 0.4 & 20.71 & 48.28 & 31.34 & 31.29 & -0.06 \\
\hline 17 & 52 & 0.5 & 0.5 & 20.55 & 48.45 & 31.54 & 31.45 & -0.09 \\
\hline 17 & 52 & 0.03 & 0.03 & 22.97 & 46.02 & 29.12 & 29.03 & -0.09 \\
\hline 18 & 52 & 0.03 & 0.03 & 23.82 & 46.18 & 28.26 & 28.18 & -0.08 \\
\hline 19 & 52 & 0.03 & 0.03 & 24.67 & 46.33 & 27.40 & 27.33 & -0.07 \\
\hline 20 & 52 & 0.03 & 0.03 & 25.51 & 46.48 & 26.54 & 26.49 & -0.06 \\
\hline 21 & 52 & 0.03 & 0.03 & 26.36 & 46.64 & 25.68 & 25.64 & -0.04 \\
\hline 17 & 52 & 0.5 & 0.5 & 20.55 & 48.45 & 31.54 & 31.45 & -0.09 \\
\hline 17 & 51 & 0.5 & 0.5 & 20.43 & 47.56 & 30.65 & 30.57 & -0.08 \\
\hline 17 & 50 & 0.5 & 0.5 & 20.32 & 46.68 & 29.75 & 29.68 & -0.07 \\
\hline 17 & 49 & 0.5 & 0.5 & 20.21 & 45.79 & 28.86 & 28.79 & -0.06 \\
\hline 17 & 48 & 0.5 & 0.5 & 20.09 & 44.90 & 27.96 & 27.91 & -0.06 \\
\hline
\end{tabular}

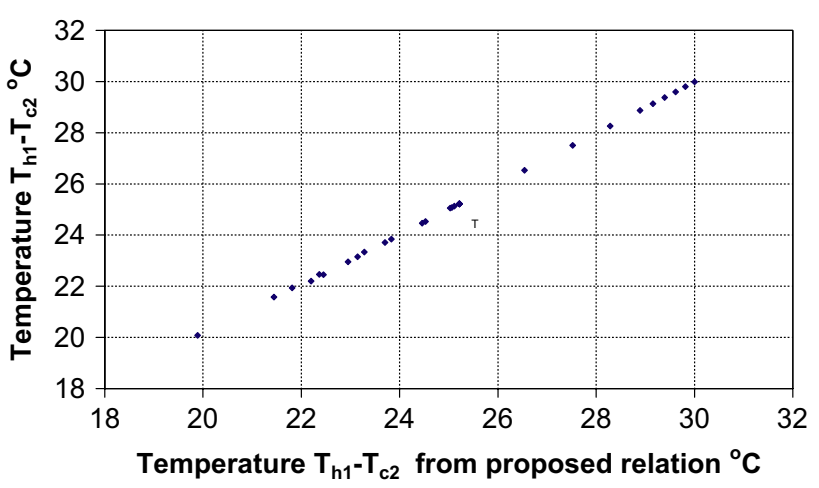

Fig. 11 A comparison between the temperature difference $\left(\Delta T_{2}\right)$ as obtained using the simulator and as calculated from the proposed relation $(27)$

The points in Fig. 10 are located along the line $(y=x)$, which indicates that the proposed relation (18) is highly accurate.

Data used in the above analysis are shown in Tables 1 and 2 .

The inlet and outlet temperatures, mass flow rates, the temperature differences as obtained from the simulator and from the proposed relation (18) and their differences for different mass flow rates of both fluids are presented in Table 1.

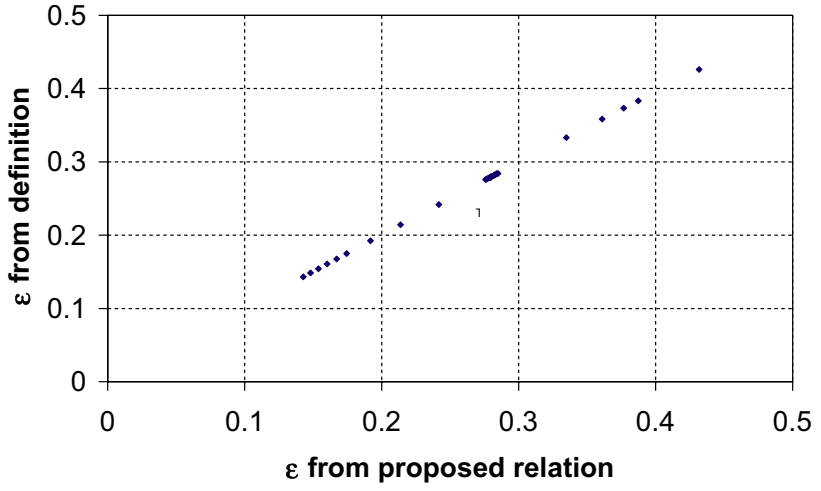

Fig. 12 A comparison between the heat transfer effectiveness as calculated from the definition (1) and from the proposed relation (28)

An example of inlet and outlet temperatures, mass flow rates, temperature differences obtained from the simulator and from the proposed relation (18), and their differences for equal mass flow rates for both fluids are shown in Table 2.

The difference between $\Delta T_{2}$ as obtained from the simulator and from the proposed relation (18) corresponds to the difference between $T_{c 2}$ as calculated from the simulator and from the proposed relation (18). These differences are small and their maximum value is equal to 0.44 , so the proposed relation (18) can be considered accurate. 
Table 3 Comparison of $\Delta T_{2}$ and the effectiveness calculated from the definition and from the proposed relations (27) and (28)

\begin{tabular}{lllll}
\hline$\Delta T_{2}\left[{ }^{\circ} \mathrm{C}\right]$ from relation $(27)$ & $\Delta T_{2}\left[{ }^{\circ} \mathrm{C}\right]$ & Difference $\left[{ }^{\circ} \mathrm{C}\right]$ & $\varepsilon$ from relation $(28)$ & $\varepsilon$ from definition \\
\hline 25.21 & 25.22 & 0.01 & 0.280 & 0.279 \\
24.46 & 24.46 & 0.00 & 0.281 & 0.281 \\
23.70 & 23.71 & 0.00 & 0.282 & 0.282 \\
22.95 & 22.96 & 0.00 & 0.283 & 0.283 \\
22.20 & 22.21 & 0.00 & 0.284 & 0.284 \\
24.53 & 24.53 & 0.01 & 0.279 & 0.278 \\
23.84 & 23.84 & 0.00 & 0.278 & 0.278 \\
23.14 & 23.15 & 0.00 & 0.277 & 0.277 \\
22.45 & 22.45 & 0.00 & 0.276 & 0.276 \\
26.54 & 26.53 & -0.01 & 0.242 & 0.242 \\
27.52 & 27.51 & -0.02 & 0.214 & 0.214 \\
28.28 & 28.26 & -0.02 & 0.192 & 0.192 \\
28.89 & 28.87 & -0.02 & 0.174 & 0.175 \\
29.16 & 29.14 & -0.02 & 0.167 & 0.167 \\
29.40 & 29.38 & -0.02 & 0.160 & 0.161 \\
29.62 & 29.60 & -0.02 & 0.154 & 0.154 \\
29.82 & 29.80 & -0.02 & 0.148 & 0.149 \\
30.00 & 29.99 & -0.02 & 0.143 & 0.143 \\
23.28 & 23.34 & 0.06 & 0.335 & 0.333 \\
22.36 & 22.46 & 0.09 & 0.361 & 0.358 \\
21.81 & 21.93 & 0.12 & 0.377 & 0.373 \\
21.44 & 21.58 & 0.14 & 0.387 &
\end{tabular}

\subsection{Results of the model involving the parameter $\alpha$}

The relation (27) was verified against the data produced by a simulator of a double-tube heat exchanger. Figure 11 illustrates a comparison between the temperature difference $\left(\Delta T_{2}\right)$ obtained using the data from the simulator and the one calculated from the proposed relation (27).

In Fig. 11 there are fewer points than in Fig. 10 as the points of equal heat capacity rates of both fluids were not included. For identical heat capacity rates the relation (27) takes an indefinite value of $0 / 0$.

Figure 12 illustrates a comparison between the heat transfer effectiveness as calculated from the definition (1) and from the proposed relation (28).

The points in Figs. 11 and 12 are located along the line $(y=x)$, which indicates that the proposed relations $(27,28)$ are highly accurate.

The input and output simulator data are the same as presented in Table 1; therefore, in Table 3 only temperature differences $\left(\Delta T_{2}\right)$ obtained from the simulator and from the proposed relation (27), and their differences, as well as the values of effectiveness calculated from the definition and from the proposed relation (28) are presented.

On the basis of the data presented in Table 3, a high degree of accuracy of the proposed relations (27) and (28) can be seen.

\section{Conclusion}

In the present paper, the performance of a double-tube counter-flow heat exchanger under off-design conditions was analysed. Water was used as heat transfer fluids. The hot fluid was flowing inside the smaller tube, while the one heated inside the larger tube.

During operation of the counter-flow heat exchanger, the parameters (temperatures and mass flow rates) at its inlet change, which leads to a change in its performance. Heat transfer effectiveness is most often used to describe the heat exchanger performance under off-design conditions. In this paper, an attempt was made to obtain a new relation for the heat transfer effectiveness of the counter-flow heat exchanger as a function of the parameters at its inlet (temperatures of both fluids at the inlet of the heat exchanger and the mass flow rates).

To this end, the counter-flow heat exchanger was considered as a 'black box', and the effect of the inlet parameters [the inlet temperature $\left(T_{h 1} ; T_{c 1}\right)$ and the mass flow rates $\left.\left(\dot{m}_{h}, \dot{m}_{c}\right)\right]$ on the heat transfer effectiveness was investigated.

The data obtained from the counter-flow heat exchanger simulator proved that the changes in inlet temperatures $\left(T_{h 1}, T_{c 1}\right)$ cause linear changes in outlet temperatures (Figs. 4, 5) for constant mass flow rates. For constant inlet temperatures, the changes in mass flow rates have 
a non-linear effect on the outlet temperature changes (Figs. 6, 7). The nature of these changes was approximated by power functions.

Following this analysis, some conclusions were drawn, and a relation for the heat transfer effectiveness as a function of the inlet parameters was obtained. Unfortunately the proposed relation (18 or 5) contains five constant coefficients which need to be determined based on the real or simulator data. The values of these coefficients vary according to the type of counter-flow heat exchanger; they depend on the heat exchanger geometry (inner and outer diameter, length of the heat exchanger) and the properties of heat transfer fluids.

The advantage of the proposed relation (18) is that it is a function of only inlet parameters (two temperatures and mass flow rates). Its disadvantage, however, is quite a large number of constant coefficients that need to be specified for the given type of counter-flow heat exchanger. This equation can be used for both equal and different mass flow rates (fluid heat capacities).

Due to a large number of constant coefficients in the relation, a new approach was chosen, namely to investigate a parameter defined as the ratio of the minimum to the actual arithmetic mean temperature difference. The analysis shown that the parameter $(\alpha)$ defined in this way is a function of two variables: the ratio of heat capacity rates $C$, and $N T U$; it contains no constant coefficients. In order to determine $N T U$, the overall heat transfer coefficient $U$ needs to be determined. This equation can only be used for different mass flow rates (fluid heat capacities), since for equal mass flow rates (fluid heat capacities) the relation takes the indefinite value $0 / 0$.

The proposed relations $(5,18,27$ and 28) were verified against the data produced by a simulator of a double-tube counter-flow heat exchanger. All the proposed equations revealed to be highly accurate (Figs. 10, 11, 12). The difference between the outlet temperature as obtained from the simulator and from the proposed relations (18) and (27) is in the range of $\pm 0.5^{\circ} \mathrm{C}$.

Taking into account the measurement errors of the measured values (temperatures and mass flow rates), it is expected that the accuracy of the proposed equations will be less and in the range of $\pm 2{ }^{\circ} \mathrm{C}$, because temperature measurement is usually implemented with an accuracy of $\pm 1.0{ }^{\circ} \mathrm{C}$. Considering the measurement errors of the temperatures and mass flow rates, the accuracy of the proposed equations should be expected to be in a similar range as in [6].

Open Access This article is distributed under the terms of the Creative Commons Attribution License which permits any use, distribution, and reproduction in any medium, provided the original author(s) and the source are credited.

\section{References}

1. Kostowski E (2000) Heat transfer (in Polish). WPS Gliwice, Poland

2. Wiśniewski TS (1997) Heat transfer (in Polish). WNT Warszawa, Poland

3. Cengel YA (1998) Heat transfer. McGraw-Hill, New York

4. Cengel YA (2007) Heat and mass transfer. McGraw-Hill, New York

5. Sahin B, Ust Y, Teke I, Erdem HH (2010) Performance analysis and optimization of heat exchangers: a new thermoeconomic approach. Appl Therm Eng 30:104-109

6. Patrascioiu C, Radulescu S (2012) Modeling and simulation of the double tube heat exchanger case studies. In: Advances in Fluid Mechanics \& Heat \& Mass Transfer, pp 35-41. ISBN: 978-1-61804-114-2

7. Lerou PPPM, Veenstra TT, Burger JF, ter Brake HJM, Rogalla $H$ (2005) Optimization of counterflow heat exchanger geometry through minimization of entropy generation. Cryogenics 45:659-669

8. Swamee PK, Aggarwal N, Aggarwal V (2008) Optimum design of double pipe heat exchanger. Int J Heat Mass Transf 51:2260-2266

9. Mohamed HA (2006) Entropy generation in counter flow gas to gas heat exchangers. J Heat Transfer 128:87-92

10. Cabezas-Gomez L, Navarro HA, Saiz-Jabardo JM, de Morais Hanriot S, Maia CB (2012) Analysis of a new cross flow heat exchanger flow arrangement-Extension to several rows. Int $\mathrm{J}$ Therm Sci 55:122-132

11. Fakheri A (2008) Efficiency and effectiveness of heat exchanger series. J Heat Transfer 130(8). doi:10.1115/1.2927404

12. Ahmad (2007) Heat exchanger efficiency. J Heat Transfer 129(9):1268-1276

13. Bradley JC (2010) Counterflow, crossflow and cocurrent flow heat transfer in heat exchangers: analytical solution based on transfer units. Heat Mass Transfer 46:381-394

14. Nellis GF, Pfotenhauer JM (2005) Effectiveness-NTU relationship for a counterflow heat exchanger subjected to an external heat transfer. J Heat Transfer 127:1071-1073

15. Zheng H, Bai J, Wei J, Huang L (2011) Numerical simulation about heat transfer coefficient for the double pipe heat exchangers. Appl Mech Mater 71-78:2477-2580

16. Bracco S, Faccioli I, Troilo M (2007) A numerical discretization method for the dynamic simulation of a double-pipe heat exchanger. Int J Energy 1(3):47-58

17. Bahadori A (2011) Simple method for estimation of effectiveness in one tube pass and one shell pass counter-flow heat exchangers. Appl Energy 88:4191-4196

18. Laskowski R (2011) The concept of a new approximate relation for exchanger heat transfer effectiveness for a cross-flow heat exchanger with unmixed fluids. J Power Technol 91(2):93-101

19. Gogół W (1984) Heat transfer tables and graphs (in Polish). WPW Warszawa, Poland

20. Hobler T (1953) Movement of heat and heat exchangers (in Polish). PWT Warszawa, Poland

21. Holman JP (2010) Heat transfer. McGraw-Hill, New York

22. Stefanowski B, Staniszewski B (1957) Technical thermodynamics (in Polish). PWN Warszawa, Poland

23. Staniszewski B (1979) Heat transfer (in Polish). PWN Warszawa, Poland

24. Szargut J (1974) Thermodynamics (in Polish). PWN Warszawa, Poland

25. Madejski J (1963) Theory of heat transfer (in Polish). PWN Poznań, Poland 